\title{
Numerical and Physical Study on a Cylindrical Tundish Design to Produce a Swirling Flow in the SEN During Continuous Casting of Steel
}

\author{
PEIYUAN NI, DONGXING WANG, LAGE TORD INGEMAR JONSSON, \\ MIKAEL ERSSON, TING-AN ZHANG, and PÄR GÖRAN JÖNSSON
}

\begin{abstract}
A new tundish design was investigated using both water model experiments and numerical simulations. The results show that the Reynolds Stress Model simulation results agree well with the Particle Image Velocimetry-measured results for water model experiments. A strong swirling flow in the Submerged Entry Nozzle (SEN) of the new tundish was successfully obtained, and the tangential velocity in the region near SEN inlet could reach a value of around $3.1 \mathrm{~m} / \mathrm{s}$. A high value of the shear stress was found to exist on the SEN wall, due to the strong swirling flow inside the SEN. This large shear stress leads to the dissipation of the rotational momentum of the steel flow. Thus, the maximum tangential velocity of the steel flow decreases from $3.1 \mathrm{~m} / \mathrm{s}$ at around the SEN inlet to $2.2 \mathrm{~m} / \mathrm{s}$ at a location close to the SEN outlet. In addition, the near-wall region has a high pressure, which is larger than the atmospheric pressure, due to the centrifugal effect. The calculated swirl number, with the value of around 1.6 at SEN inlet, illustrates that the current design can produce a similar strong swirling flow compared to the swirl blade method and the electromagnetic stirring method, while this is obtained by simply changing the steel flow path in tundish instead of using additional device to influence the flow.
\end{abstract}

DOI: $10.1007 / \mathrm{s} 11663-017-1057-\mathrm{y}$

(C) The Author(s) 2017. This article is an open access publication

\section{INTRODUCTION}

IT is well known that the steel flow pattern in the continuous casting mold is very important for the quality of steel products. Some undesirable flows, like vortex formation and meniscus fluctuation, in the mold may lead to serious surface or internal defects. As the connecting part between the tundish and the mold, the Submerged Entry Nozzle (SEN) plays an important role in continuous casting. This is partly due to the fact that the steel flow characteristics in the mold are directly influenced by the upstream SEN outlet flow. In the past,

PEIYUAN NI is with the Key Laboratory of Ecological Metallurgy of Multi-metal Intergrown Ores of Education Ministry, School of Metallurgy, Northeastern University, Shenyang 110819, China, and also with the Division of Processes, Department of Material Science and Engineering, KTH Royal Institute of Technology, 10044 Stockholm, Sweden. Contact e-mail: peiyuann@kth.se DONGXING WANG and TING-AN ZHANG are with the Key Laboratory of Ecological Metallurgy of Multi-metal Intergrown Ores of Education Ministry, School of Metallurgy, Northeastern University. LAGE TORD INGEMAR JONSSON, MIKAEL ERSSON, and PÄR GÖRAN JÖNSSON are with the Division of Processes, Department of Material Science and Engineering, KTH Royal Institute of Technology.

Manuscript submitted February 6, 2017.

Article published online August 1, 2017. many studies have been carried out in order to understand the steel flows in SENs under various conditions and to further improve the bulk flow pattern in the mold. ${ }^{[1-23]}$ Specifically, the effects of the nozzle type (straight or bifurcated), ${ }^{[1,2]}$ SEN port design (number, shape, angle, thickness), ${ }^{[3-13]}$ argon injection in SENs, ${ }^{[5,15-21]}$ SEN immersion depth, ${ }^{[6,13]}$ slide gate position, ${ }^{[5]}$ and nozzle clogging ${ }^{[17,22]}$ on the steel flows have been investigated. These studies improved the understanding of the steel flow characteristics in SENs which contributed to the steel flow optimization. For example, the jet angle was found mainly depending on the port angle. ${ }^{[3]}$ Argon gas injection was found to blend the port jet angle upwards and to enhance the turbulence level. ${ }^{[5]} \mathrm{A}$ square-shaped SEN port induces flows with less turbulence than a circular-shaped port at a deep immersion position, whereas at a shallow immersion position the square-shaped port induces larger turbulent conditions at the meniscus level. ${ }^{[7]}$ The tangential SEN port design, where four horizontal nozzle ports are located at the tangential direction of the SEN pipe circumference, was found to effectively reduce the center porosity and improve the chemical homogeneity. ${ }^{[10,11]}$ However, a further improvement on the flow performance based on the SEN design and parameter control seems to face challenges. Therefore, in recent years, the use of Electromagnetic Braking in the mold to 
control the outlet flow from SEN ports has been investigated as a measure to stabilize the steel flow. ${ }^{[19,24-26]}$ This method has shown the ability to stabilize the steel flow at the mold surface region for small level fluctuations. ${ }^{[19,26]}$ However, its application relies on costly equipment and also requires the consumption of electricity. Furthermore, it is sometimes difficult to use this method to accurately control the flow pattern in a mold, since the original upstream flow from the SEN port is unknown. This is especially true when some undesirable flows from the SEN ports happen, like biased flow from the ports of the bifurcated SEN or flow fluctuation.

In recent years, the swirling flow in the SEN has been found to effectively optimize the steel flow pattern in the mold during the continuous casting of steel, e.g., by decreasing the penetration depth of the SEN outlet flow, enhancing the heat and mass transfer near the meniscus, improving the flow stability, reducing the surface defects of the steel product, enhancing the flow uniformity at the SEN port area, and preventing the clogging of the SEN port. ${ }^{[27,28]}$ In addition, previous studies show that a strong swirling steel flow can be obtained in the SENs and in molds. ${ }^{[27-35]}$ This means that the technologies for a swirling flow in the SENs has the potential to replace the electromagnetic stirring in molds. ${ }^{[10,11,36,37]}$ The swirling flow inside the SEN was probably first proposed by Yokoya et al. ${ }^{[29]}$ in 1994. Thereafter, many studies have been carried out to investigate the steel flow phenomena in molds, for both the slab and the billet casting, using a swirling flow in SENs. ${ }^{[27-35]}$ This is a way to control the steel flow in molds in a root manner by optimizing the SEN port flow with a rotational velocity component. Overall, two methods have mainly been investigated to produce a swirling flow in SENs. The first method is the swirl blade method, ${ }^{[27-33]}$ i.e., by installing a swirl blade inside the nozzle. The other one is the electromagnetic stirring method, ${ }^{[34,35]}$ which is realized by installing an electromagnetic stirring equipment outside the SEN. The swirl blade method is an energy-saving method, which uses the head difference between the steel in tundish and that in the mold to produce the required power. However, the steel flow erosion and the nonmetallic inclusion deposition on the swirl blade may restrict its long-time usage during steel production. The electromagnetic stirring method does not have the above limitations as the swirl blade method, but it requires an investment in equipment as well as in supply of electricity. Therefore, the development of a new reliable technology to economically produce a swirling flow in SEN is still required.

Recently, a new method to produce a swirling flow in the SEN was reported by $\mathrm{Ni}$ et al., ${ }^{[38]}$ which uses a cylindrical tundish design to produce a rotational steel flow inside it. When the rotational steel flows from the cylindrical tundish into the SEN, a swirling flow in the SEN can be obtained, due to the rotational steel flow potential. This design gives tundish a new function as the swirling flow producer, except for its vastly investigated role to distribute and supply liquid steel to different molds and the role to carry out various metallurgical operations such as inclusion separation, alloy trimming of steel, and thermal and chemical homogenization. ${ }^{[23,39,40]}$ The numerical simulation using the realizable $k-\varepsilon$ turbulence model in combination with Standard Wall Function shows that the new design successfully produced a good swirling flow in the SEN. ${ }^{[38]}$ However, the availability of the new cylindrical tundish design to produce a swirling flow inside the SEN, so far, lacks an experimental validation. In addition, a recent study on the swirling flow in an uphill teeming ingot casting process by Bai et $a .^{[41]}$ shows that the swirling flow intensity was under-predicted using $k-\varepsilon$ type of turbulence models. However, the predicted shape of the vortex by the RSM model with Stress-Omega submodel showed a good agreement with the water model experiment observation. ${ }^{[41]}$ Furthermore, the previously obtained swirling flow intensity in the SEN is not high compared to the intensities obtained using the electromagnetic stirring method or the swirl blade method. Thus, the possibility of producing a strong swirling flow intensity using this new tundish design remains further to be investigated both experimentally and numerically, which is important for implementing new designs in industry, and is important for its potential to replace the electromagnetic stirring in molds. ${ }^{10,11,36,37]}$

In a swirling flow in SEN, a large velocity gradient normally exists in the radial direction of a cross section of the SEN, especially in the turbulent boundary layer. Anisotropy in the turbulent fluctuations may exist in such flow situations. Therefore, a good numerical solution, especially for turbulent properties, seems very important to gain good knowledge on the swirling flow characteristics. In this paper, only the steel flow in the cylindrical part of the tundish with the new parameter design was investigated, based on both numerical simulations and water model experiments. Note that the cylindrical part of the tundish is the only cause for creating a swirling flow inside the SEN. The main aim of this study is to understand the potential of this method for obtaining a strong swirling flow intensity, to further understand the swirling flow characteristics, and to validate the numerical model by water model experiments. Both the realizable $k-\varepsilon$ model with Enhanced Wall Treatment (EWT) and the Reynolds Stress Model (RSM) model with the Stress-Omega submodel were used to solve the steel flow. The RSM model can take into account the possible anisotropic turbulent fluctuations in the swirling flow. Moreover, fine grids were used in the near SEN wall region to resolve the boundary layer. In addition, novel water model experiments were carried out to show the swirling flow behavior. The PIV-measured water model results were compared to the results from numerical simulations to show the model performances. Finally, the predicted swirling flow by the validated numerical model and its comparison to the swirling flow obtained from the other methods, e.g., the electromagnetic stirring method and the swirl blade method, were analyzed.

\section{MODEL DESCRIPTION}

The geometry and dimension of the cylindrical tundish design are shown in Figure 1. The 
computational fluid dynamics model and the physical model were built up with the same dimension as the original design in Figure 1. Water was used in the physical experiment to simulate the steel flow. This is due to the fact that water at room temperature has a similar kinematic viscosity as the liquid steel at around $1773 \mathrm{~K}\left(1500{ }^{\circ} \mathrm{C}\right)$. Therefore, the Reynolds Number, with the value of around 44,000 based on tundish inlet flow, and the Froude Number are the same in these systems, which guarantees their flow similarity.

\section{A. Mathematical Model}

A three-dimensional model of the new tundish design was developed, which is in a Cartesian coordinate system. The steel density and viscosity are $7000 \mathrm{~kg} / \mathrm{m}^{3}$ and $0.0064 \mathrm{~kg} /(\mathrm{m} \mathrm{s})$, respectively.

\section{Model assumption and boundary conditions}

The three-dimensional mathematical model for the steel flow in the cylindrical tundish is based on the following assumptions:

1. Steel behaves as an incompressible Newtonian fluid.

2. Solidification and heat transfer do not occur.

3. The slag phase at the top surface was not considered.

4. The roughness of the tundish wall was not considered.

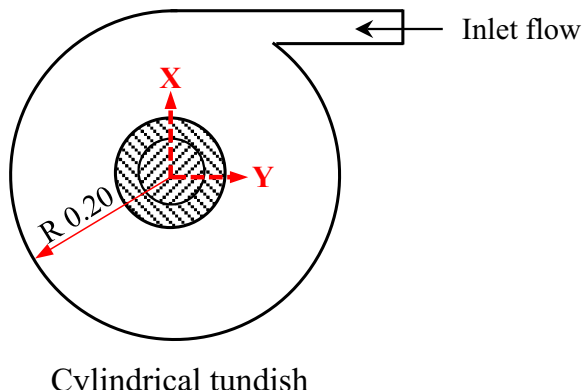

(a)

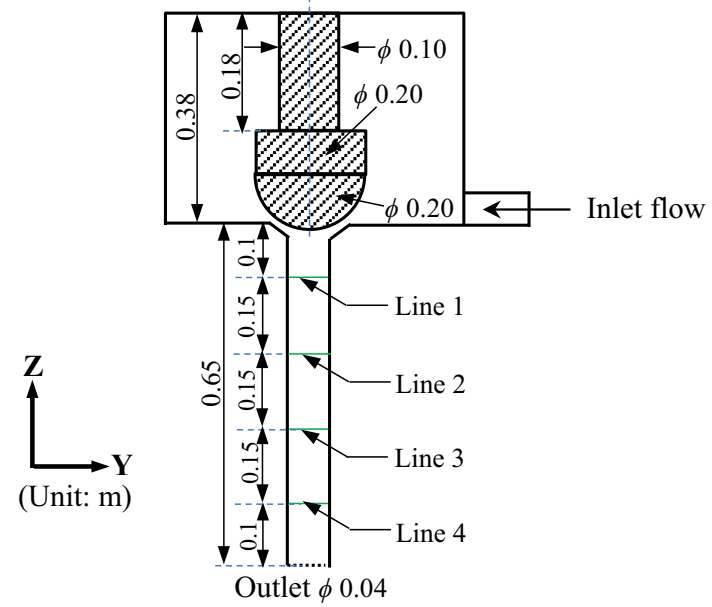

(b)

Fig. 1-Geometry and parameters of the newly designed tundish: (a) a top view of the tundish and $(b)$ a front view of the tundish.
5. The constant liquid steel flow rate, $5.0 \mathrm{~m}^{3} / \mathrm{h}$, was fixed at the inlet of the tundish.

6. The pressure at the SEN outlet was constant and equal to the atmospheric pressure.

7. The boundary condition at the tundish wall and the top surface was a no-slip wall boundary condition.

\section{Transport equations}

The conservation of a general variable $\phi$ within a finite control volume can be expressed as a balance among the various processes, which tends to increase or decrease the variable values. The conservation equations, e.g., continuity, momentum, and turbulence equations, can be expressed by the following general equation $^{[42]}$ :

$$
\frac{\partial}{\partial t}(\rho \phi)+\frac{\partial}{\partial x_{i}}\left(\rho \phi u_{i}\right)=\frac{\partial}{\partial x_{i}}\left(\Gamma_{\phi} \frac{\partial \phi}{\partial x_{i}}\right)+S_{\phi},
$$

where the first term on the left-hand side is the change of $\phi$ with time, the second term on the left-hand side represents the transport due to convection, and the first term on the right-hand side expresses the transport due to diffusion where $\Gamma_{\phi}$ is the diffusion coefficient and it is different in different turbulence models. ${ }^{[43-46]}$ Furthermore, the second term on the right-hand side is the source term.

\section{Turbulence modeling}

The realizable $k-\varepsilon$ turbulence model ${ }^{[43]}$ in combination with the Enhanced Wall Treatment model ${ }^{[44]}$ was first used to produce an initial flow field. Then, based on this flow field, the RSM model ${ }^{[44-46]}$ combined with the Stress-Omega submodel ${ }^{[44,47]}$ was used to simulate the steel flow in the cylindrical tundish. In this way, the computer calculation time required to obtain a developed flow could be reduced, which is important since the RSM model is very time consuming. The Stress-Omega submodel is good for modeling flows over the curved surfaces and swirling flows. ${ }^{[44]}$ The exact equation for solving the Reynolds stresses in the RSM model is as follows:

$$
\begin{aligned}
& \underbrace{\frac{\partial}{\partial t}\left(\rho \overline{u_{i}^{\prime} u_{j}^{\prime}}\right)}_{\text {local time derivative }}+\underbrace{\frac{\partial}{\partial x_{k}}\left(\rho u_{k} \overline{u_{i}^{\prime} u_{j}^{\prime}}\right)}_{\text {convection }}=\underbrace{\frac{\partial}{\partial x_{k}}\left(\frac{\mu_{t}}{\sigma_{k}} \frac{\partial \overline{u_{i}^{\prime} u_{j}^{\prime}}}{\partial x_{k}}\right)}_{\text {turbulent diffusion }} \\
& +\underbrace{\frac{\partial}{\partial x_{k}}\left[\mu \frac{\partial}{\partial x_{k}} \overline{u_{i}^{\prime} u_{j}^{\prime}}\right]}_{\text {molecula rdiffusion }}-\rho \underbrace{\left(\overline{u_{i}^{\prime} u_{j}^{\prime}} \frac{\partial u_{j}}{\partial x_{k}}+\overline{u_{i}^{\prime} u_{j}^{\prime}} \frac{\partial u_{i}}{\partial x_{k}}\right)}_{\text {stress production }} \\
& +\underbrace{p^{\prime}\left(\frac{\partial u_{i}^{\prime}}{\partial x_{j}}+\frac{\partial u_{j}^{\prime}}{\partial x_{i}}\right)}_{\text {pressure strain }}-2 \mu \underbrace{\overline{\frac{\partial u_{i}^{\prime}}{\partial x_{k}} \frac{\partial u_{j}^{\prime}}{\partial x_{k}}}}_{\text {dissipation }} \\
& \underbrace{-2 \rho \Omega_{k}\left(\overline{u_{j}^{\prime} u_{m}^{\prime}} \varepsilon_{i k m}+\overline{u_{i}^{\prime} u_{m}^{\prime}} \varepsilon_{j k m}\right)}_{\text {production by system rotation }} \\
& +\underbrace{S_{\text {user }}}_{\text {user-defined source term }}
\end{aligned}
$$




$$
\mu_{t}=\alpha^{*} \frac{\rho k}{\omega}
$$

where $\sigma_{k}$ is equal to $2.0, \alpha^{*}$ is the coefficient which damps the turbulent viscosity causing a low-Reynolds number correction, $k$ is the turbulent kinetic energy per unit mass, $\omega$ is the specific dissipation rate, $\mu$ is the dynamic viscosity, $\mu_{\mathrm{t}}$ is the turbulent viscosity, $\Omega_{k}$ is the rotation vector, and $\varepsilon_{i j k}$ is the alternating symbol, with the value equal to 1 if $i, j$, and $k$ are different and in cyclic order, equal to -1 if $i, j$, and $k$ are different and in anti-cyclic order, and equal to 0 if any two indices are the same. ${ }^{[44,45]}$ The turbulent diffusion term, the pressure strain term, and the dissipation term are required to be modeled to close the equation. The detailed information for modeling these terms can be found in the work of Launder, Reece, and Rodi ${ }^{[46]}$ and the ANSYS FLUENT Theory Guide. ${ }^{[4]}$ In order to close the equation sets, the equation for the specific dissipation rate $\omega$ should be solved. In the StressOmega submodel, this is computed in the same way as when using the standard $k-\omega$ model, i.e., as follows $^{[44]}$ :

$$
\frac{\partial}{\partial t}(\rho \omega)+\frac{\partial}{\partial x_{i}}\left(\rho \omega u_{i}\right)=\frac{\partial}{\partial x_{j}}\left(\Gamma_{\omega} \frac{\partial \omega}{\partial x_{j}}\right)+G_{\omega}-Y_{\omega}+S_{\omega}
$$

where $G_{\omega}$ represents the generation of $\omega, \Gamma_{\omega}$ represents the effective diffusivity of $\omega, Y_{\omega}$ represents the dissipation of $\omega$ due to turbulence, and $S_{\omega}$ is the user-defined source term. The method to calculate these terms can be found in the work of Wilcox ${ }^{[48]}$ and in the ANSYS FLUENT Theory Guide. ${ }^{[4]}$

For the RSM model with the Stress-Omega submodel, a near-wall treatment is automatically used to perform a blending between the viscous sublayer and the logarithmic region. ${ }^{[4]}$ A very fine grid with the $y^{+}$value of the first grid smaller than 1 was used to solve the flow and its turbulent properties in the swirling flow SEN.

\section{Solution method}

The steel flow field in the new tundish design was solved using the commercial software ANSYS FLUENT $17.0^{\circledR}$. The PISO scheme was used for the pressure-velocity coupling. The PRESTO method was adopted to discretize the pressure. The governing equations were discretized using a second-order upwind scheme. The convergence criteria were as follows: the residuals of all dependent variables were smaller than $1 \times 10^{-3}$ at each time step.

\section{B. Water Model Experiment}

The water model experiment was carried out to observe the flow phenomena in the new cylindrical tundish SEN and to validate the numerical model. The setup of the water model experiment system is shown in Figure 2(a). The water model is in the same scale as the numerical model to make sure that both models have the same Froude Number and Reynolds number. The cylindrical tundish was made up using transparent plexiglass, and it is shown in Figure 2(b). The water flow rate was measured by a flow meter. The flow field in a vertical middle plane of the SEN was measured using PIV (Particle Image Velocimetry, Dantec Dynamics Ltd.), where the measured plane is located at $0.24 \mathrm{~m}$ below the tundish bottom.

\section{RESULTS}

The steel flow phenomena in the cylindrical tundish were obtained by solving the mathematical models, based on around 2 million grid cells to obtain grid independent results. The mesh was created using the cut-cell method in ANSYS Workbench 18.0, and it is mostly consisting of hexahedral grid cells. Firstly, a time-dependent solution when using the realizable $k-\varepsilon$ turbulence model was used to obtain the steel flow for the initial 355 seconds. Thereafter, the RSM model based on the solved flow field at 355 seconds was used to obtain the final solution.

Figure 3 shows the tangential steel flow velocities along Line 2 in SEN as shown in Figure 1(b). Although the CFD model is built up in a Cartesian coordinate system, the tangential velocity can easily be plotted based on the defined axis (SEN center in this paper) in the post-processing in ANSYS FLUENT. It can be seen that the steel flow velocity changes a lot. More specifically, the maximum tangential velocity increased from a value of $1.96 \mathrm{~m} / \mathrm{s}$ at 355 seconds in the realizable $k-\varepsilon$ model to $2.45 \mathrm{~m} / \mathrm{s}$ at 357 seconds in the RSM model prediction. This result means that the tangential velocity of the swirling flow is under-predicted using the realizable $k-\varepsilon$ turbulent model. This was also found by Bai et $a l .^{[41]}$ in a recent research about swirling flow in ingot casting. The possible reason is that the rotational momentum is over-dissipated when using the realizable $k-\varepsilon$ turbulence model. The steel flow velocities solved by the RSM model at 2 seconds (total time at 357 seconds), 7 seconds (total time at 362 seconds), and 12 seconds (total time at 367 seconds) are also compared in Figure 3. It can be seen that from 7 to 12 seconds the steel flow velocity changes only slightly, with the value of around 3 pct. Therefore, the flow field at 367 seconds solved by RSM was used to compare to the results of the water model experiment.

\section{A. CFD Model Validation}

The streamlines of the steel flow in the cylindrical tundish from RSM model are shown in Figure 4(a). It can be seen that a swirling steel flow was obtained in the SEN. In order to observe the water flow path inside the SEN by eyes, air inside the SEN was not removed. Figures 4(b) and (c) shows the flow path inside SEN obtained from the RSM simulations and observed from the water model experiments, respectively. It can be seen from Figures 4(b) and (c) that the numerical model-predicted flow path in the SEN is similar to the one predicted with the water model observations with a similar flow direction. Due to the swirling flow, a vortex was observed in the water model experiment, as shown 


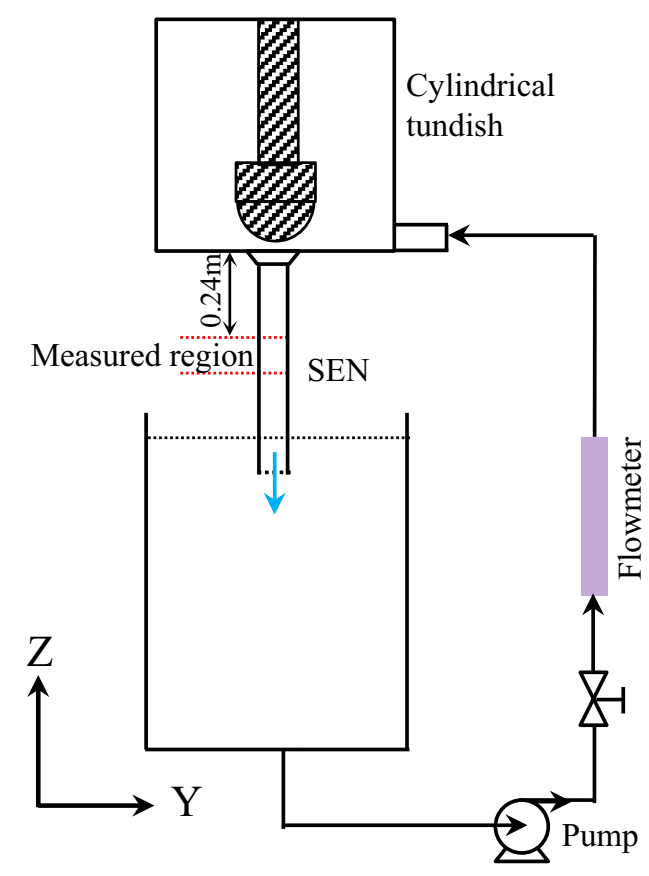

(a)

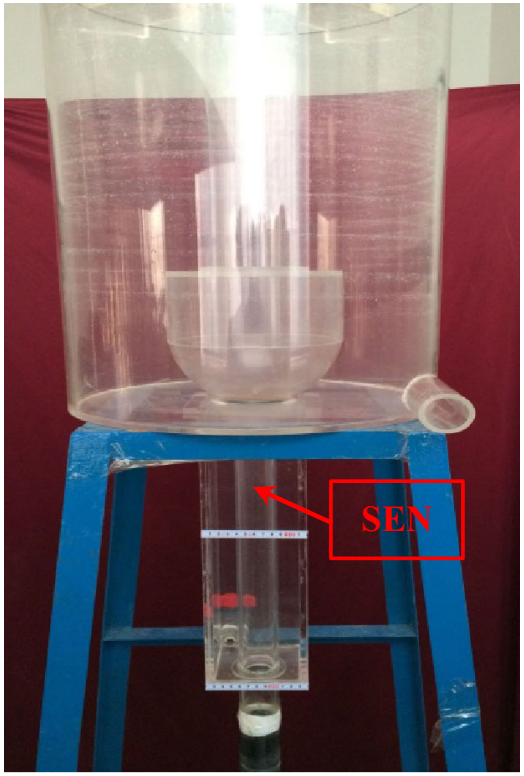

(b)

Fig. 2-(a) Schematic of the water model experiment system and (b) Plexiglass model of the cylindrical tundish used for water model experiment.

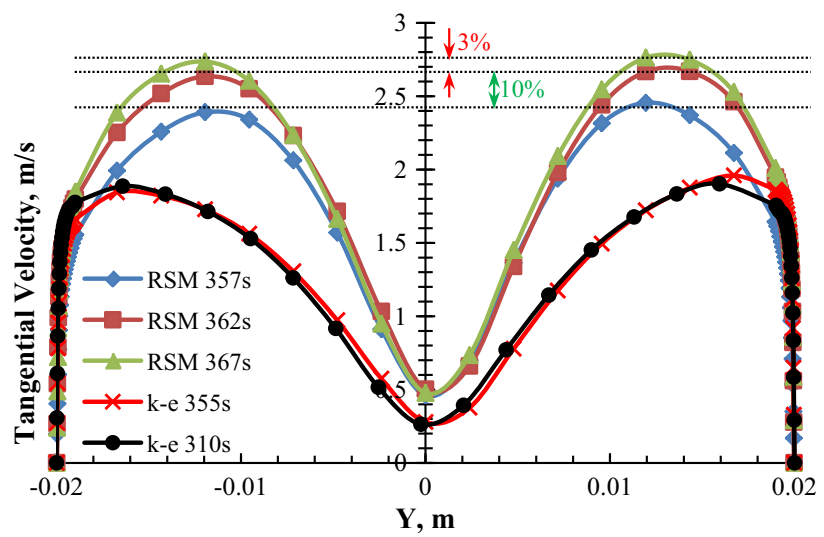

Fig. 3 - Comparison of steel flow velocity along Line 2 in tundish SEN.

in Figure 4(c). It means that this way to produce the swirling flow is effective.

Figure 5 shows the vertical velocity distributions in the middle YZ plane of the SEN both from the PIV measurements and the simulations. The location of the plotted vertical plane is shown in Figure 4(a), which is $0.24 \mathrm{~m}$ below the tundish bottom. Here, the simulation results from the RSM model prediction at 367 seconds and from the realizable $k-\varepsilon$ model prediction at 355 seconds are shown in comparison to the experimental results. It can be seen from Figure 5(a) that the flow goes upwards rather than downwards in the center of the SEN, i.e., in the opposite direction to the gravity. This is due to the strong swirling flow in the SEN, which leads to a very low pressure at the center of the SEN. Therefore, the liquid flows upwards, due to the pressure gradient, and over-runs the gravity effect. In the region close to the wall, the liquid flows downwards. Therefore, the vertical velocity has a change of the flow direction from wall to the SEN center. This can clearly be seen from the PIV-measured velocity distribution in Figure 5(a). Figure 5(b) shows the simulation results of the velocity distribution. It can be seen that the RSM-predicted results show an upward flow in the center of the SEN, which is similar to what is observed in the water model experiments. However, for predictions using the realizable $k-\varepsilon$ model, it can be seen that the velocity in the SEN center is close to zero, which is different from the water model results. In order to clearly observe the difference in model predictions, Figure 6 shows the comparison of vertical velocity distribution along the line as shown in Figure 5, which is located $0.28 \mathrm{~m}$ from the tundish bottom. It can be seen that the RSM model prediction is very close to the water model experiment measurement. The realizable $k-\varepsilon$ model gives a lower prediction in the vertical velocity magnitude, especially in the SEN center region. This is consistent with the finding that the realizable $k-\varepsilon$ model predicted a smaller tangential velocity (shown in Figure 3) and should therefore also show a lower pressure gradient in the SEN center. Figure 7 shows the comparison of static pressure predicted by RSM model and $k-\varepsilon$ model along the line in Figure 5. It can be seen that the $k-\varepsilon$ model predicts a lower pressure compared to the RSM model. Therefore, a lower pressure gradient (its difference from the atmospheric pressure) exists in the SEN center compared to that in the RSM prediction. This low pressure gradient is not enough to overcome the gravity to reach a high upward water flow velocity, which is observed in the water model experiment as well as the RSM model prediction. 
From the above investigation, it can be concluded that the cylindrical tundish is an effective way to produce a swirling flow in the SEN. Furthermore, the RSM model prediction results are more close to the PIV-measured results, compared to the realizable $\mathrm{k}-\varepsilon$ model predictions. In the following, the predicted results using the RSM model at 367 seconds will be used to show the swirling flow properties in the SEN of the newly designed cylindrical tundish, with the area ratio of the tundish inlet to SEN outlet being 1 .

\section{B. Swirling Flow in the SEN}

Figure 8 shows the steel flow velocity distribution, the pressure distribution, and the turbulent kinetic energy distribution in the SEN. It can be seen from Figure 8(a) that a high velocity exists at the near-wall region of the SEN, which is much larger than that at the nozzle center. The magnitude of the steel flow velocity in the near-wall region decreases with an increasing distance from the SEN inlet, with the value decreasing from around $3.8 \mathrm{~m} / \mathrm{s}$ at point $\mathrm{A}$ to around $2.7 \mathrm{~m} / \mathrm{s}$ at point $\mathrm{B}$ in Figure 8(a). This is due to the dissipation of the rotational velocity due to the wall shear stress. It can be observed from Figure 8(b) that a high pressure exists in the near-wall region of the SEN. This pressure is larger than the atmospheric pressure by around 30 pct, while the SEN center has a pressure lower than the atmospheric pressure by around 30 pct. This should be a common phenomenon in a swirling steel flow due to the

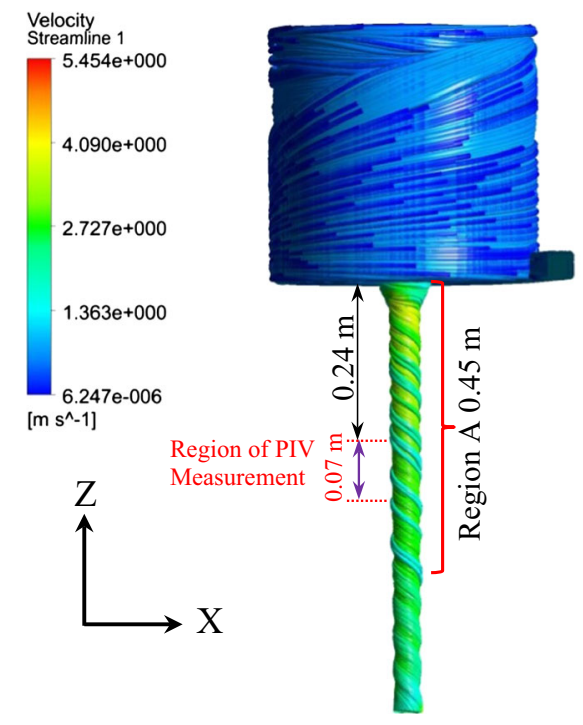

(a)

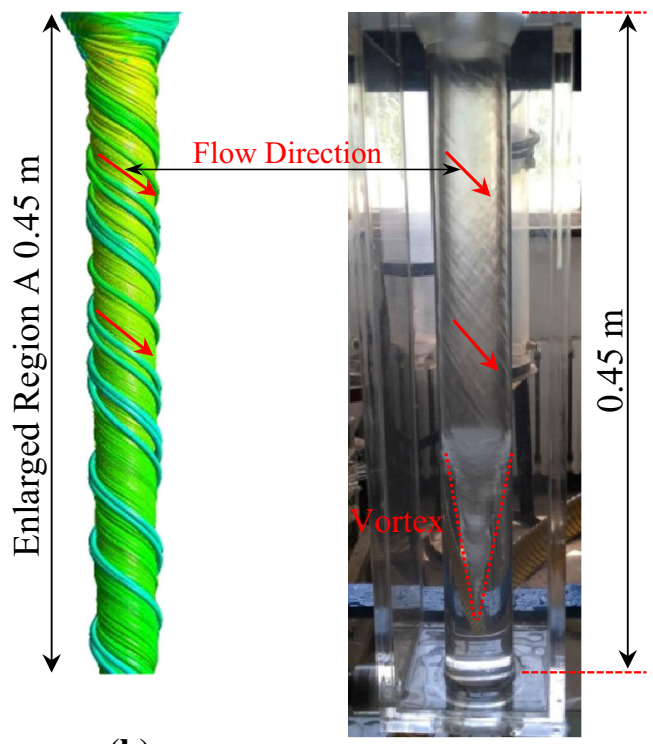

(c)

Fig. 4-Flow paths: (a) streamline in the cylindrical tundish, (b) streamline inside the SEN, and (c) water flow path in the SEN.

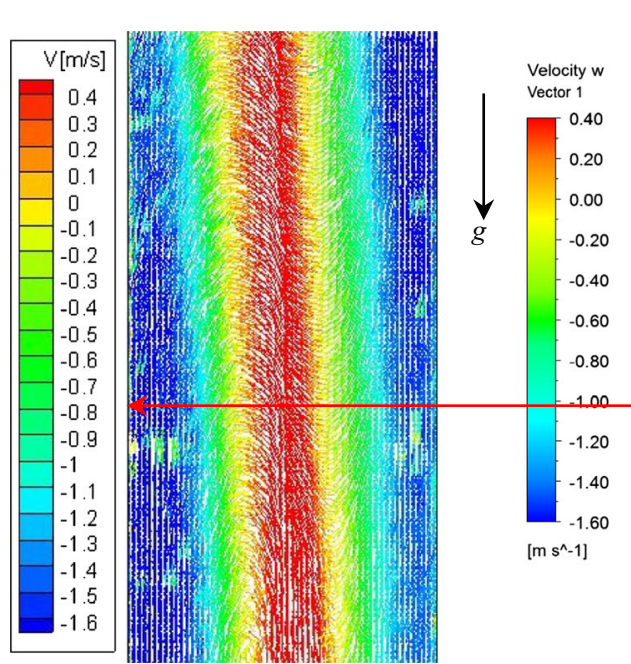

(a) Water model experiment

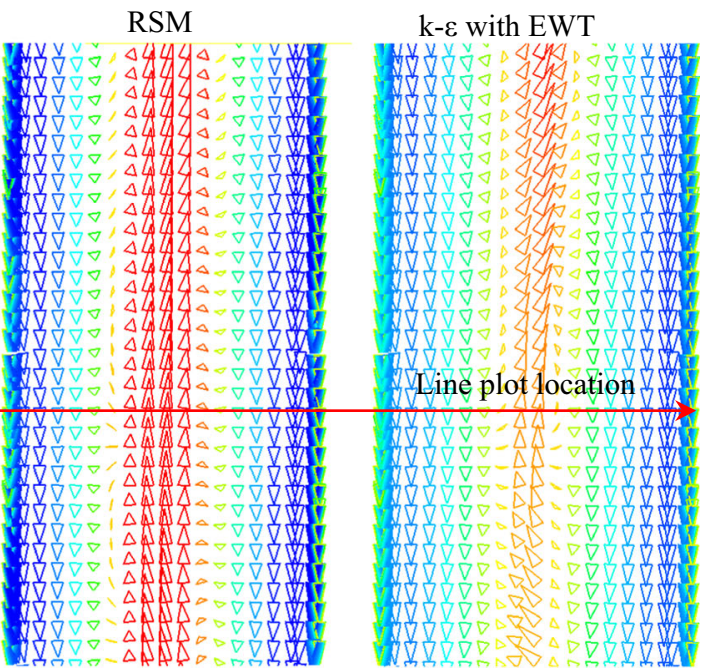

(b) Simulation Results

Fig. 5-Flow velocity in the swirling flow SEN: $(a)$ water model experiment and $(b)$ simulation. 


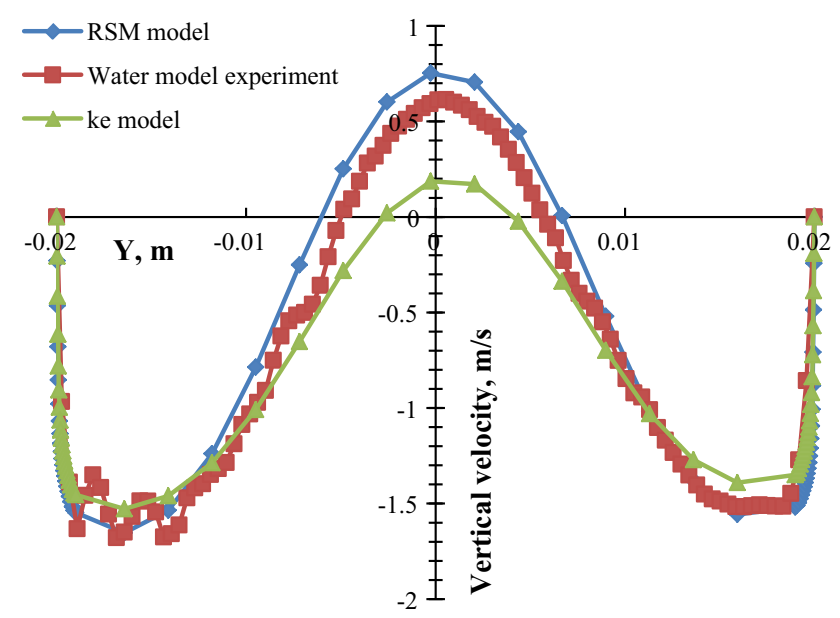

Fig. 6 - Comparison of vertical velocity in the swirling flow SEN.

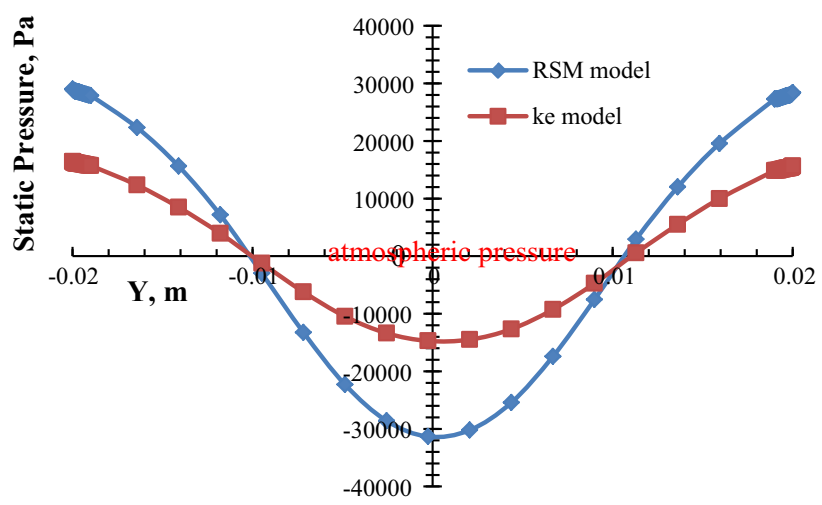

Fig. 7- Comparison of static pressure in the swirling flow SEN predicted by different models. centrifugal effect. Figure 8(c) shows the turbulent kinetic energy distribution in the SEN. It can be seen that the values of turbulent kinetic energy decrease from around $0.1 \mathrm{~m}^{2} / \mathrm{s}^{2}$ at the top of the SEN to around 0.02 $\mathrm{m}^{2} / \mathrm{s}^{2}$ near the SEN outlet, and the values tend to become similar at the wall region of the same height. This may be due to the dissipation of the rotational velocity as well as the turbulence level, which results in the decrease of flow velocity. Furthermore, the flow may be more and more close to a developed flow while flowing downwards.

Figure 9 shows the distribution of the tangential velocity, total velocity, and pressure in different cross sections of the SEN. It can be seen from the flow vectors that a good swirling flow was obtained. From the top of the SEN (Figure 9(a1)) to the bottom of the SEN (Figure 9(d1)), the magnitude of the tangential velocity decreases due to the dissipation of the rotational momentum, with the maximum value decreasing from 3.1 to $2.2 \mathrm{~m} / \mathrm{s}$. This decrease of tangential velocity leads to a decrease of the velocity magnitude from the top to the bottom of the SEN, as shown in Figure 9(a2) through (d2). Due to the decrease of the rotational momentum, the maximum pressure in the cross section also decreases, from around 37,700 $\mathrm{Pa}$ in Figure 9(a3) decreasing to around 22,500 $\mathrm{Pa}$ in Figure 9(d3).

Figure 10 shows the velocity distributions along different lines (shown in Figure 1(b)) in the SEN. It can be seen from Figures 10(a) and (b) that the velocity magnitude can reach a value of around $3.5 \mathrm{~m} / \mathrm{s}$, with a tangential velocity of $3.1 \mathrm{~m} / \mathrm{s}$. This means that a very strong swirling flow was formed in the SEN when using the current tundish design. Due to the strong swirling flow, the vertical velocity distribution changes a lot. In the region of the SEN wall side, the steel flows

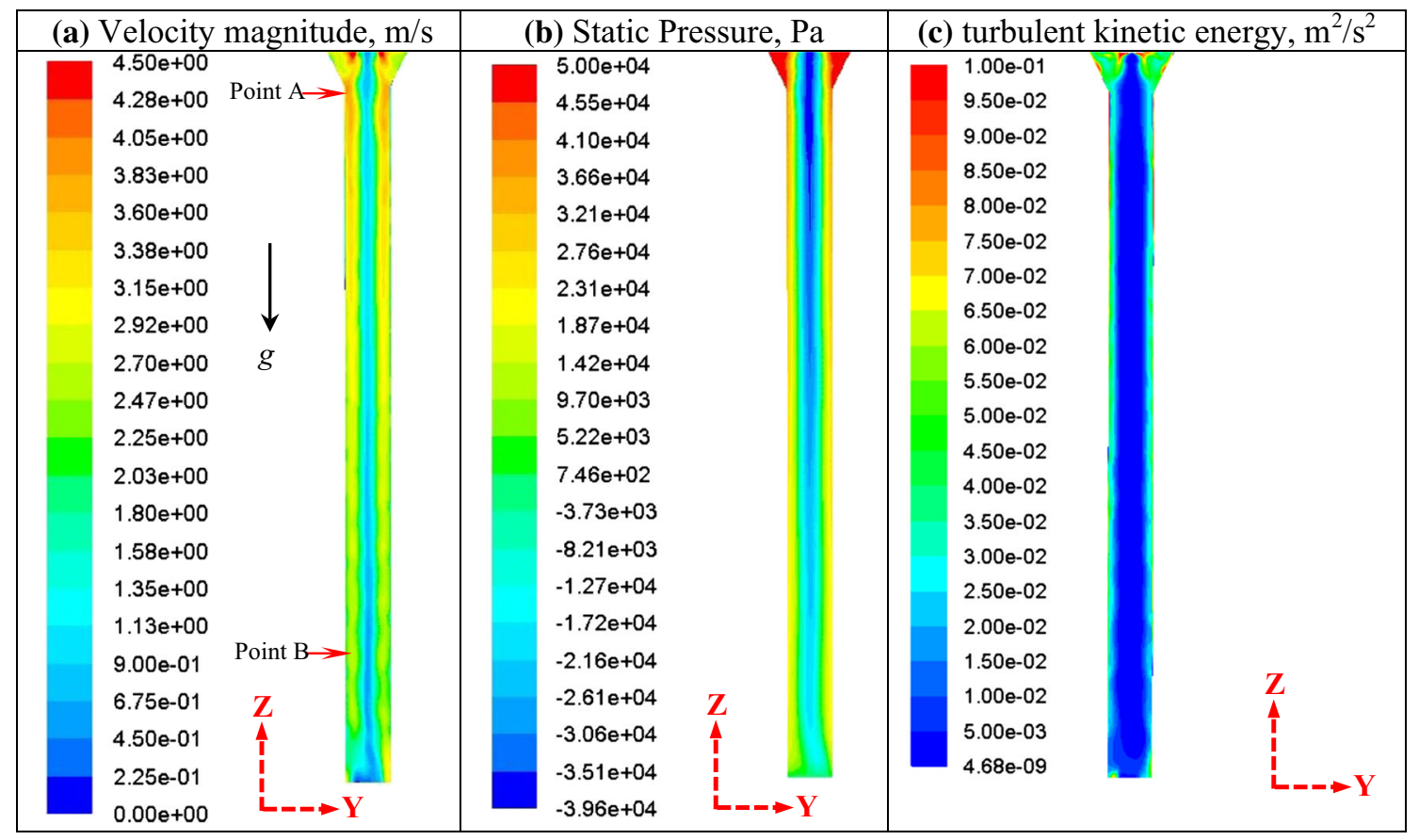

Fig. 8-Velocity, pressure, and turbulent kinetic energy distributions in the YZ middle plane of the SEN. 


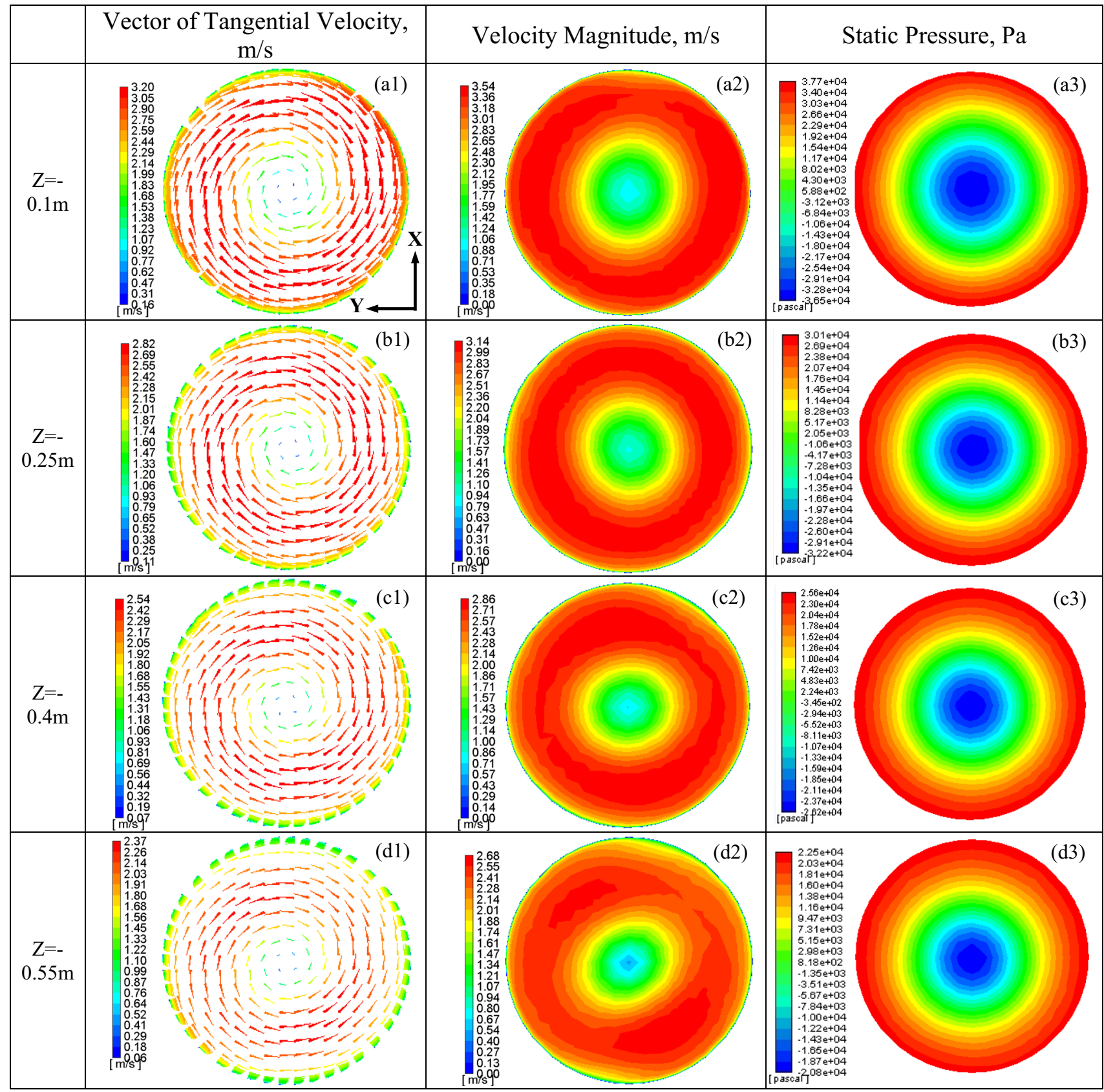

Fig. 9-Distributions of the tangential velocity, total velocity, and static pressure in different cross sections of the SEN.

downwards, while the steel flows upwards in the center of the SEN. This is due to the low pressure in the center of the SEN, which is caused by the centrifugal effect, as illustrated in Figure 10(c). Therefore, the swirling flow changes the flow characteristics in the vertical direction. The velocity magnitude of the steel flow decreases from the top to the bottom of the SEN. This is mainly due to the decrease of the tangential velocity. More specifically, it decreases from $3.1 \mathrm{~m} / \mathrm{s}$ in Line 1 to around $2.2 \mathrm{~m} / \mathrm{s}$ in Line 4, i.e., a decrease by around 29 pct. The reason for the decrease of the swirling intensity is shown in Figure 11, where the wall shear stress of the SEN is presented. It can be seen that a high wall shear stress exists in the SEN. This is a common phenomenon for the swirling flow situation, since a large velocity gradient exists at the near-wall region. In the current setup, the maximum shear stress can reach around $380 \mathrm{~Pa}$. The values of shear stress are in the range of 100 to $300 \mathrm{~Pa}$ in most part of the SEN wall. This shear stress can lead to a dissipation of the swirling flow intensity when steel flows down from the SEN top to bottom, as shown in Figure 10(b). Therefore, the SEN length is an important parameter while designing a swirling flow at the SEN outlet. 


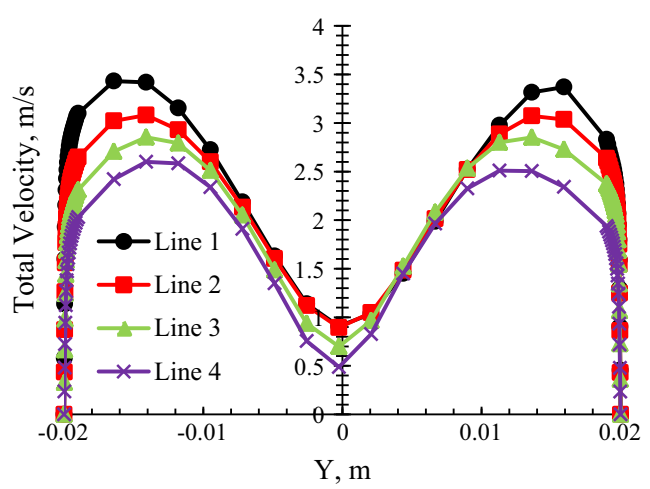

(a)

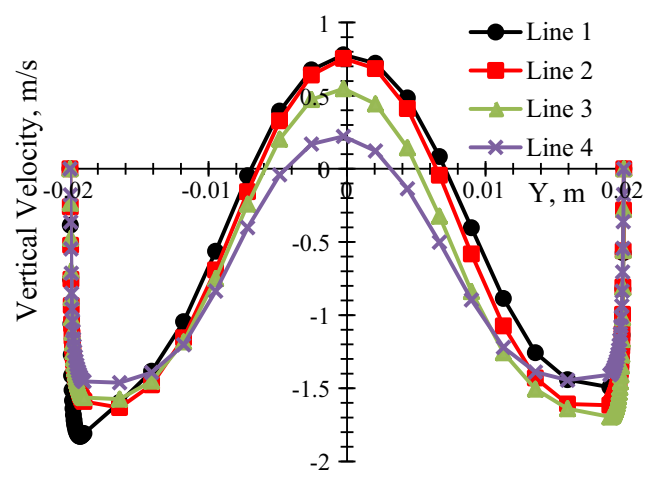

(c)

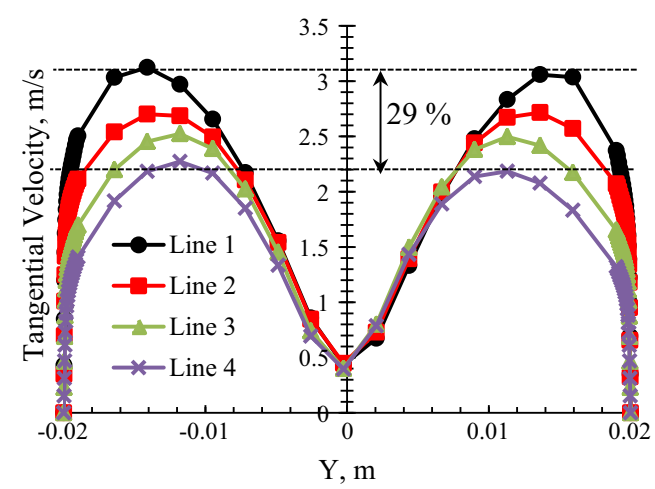

(b)

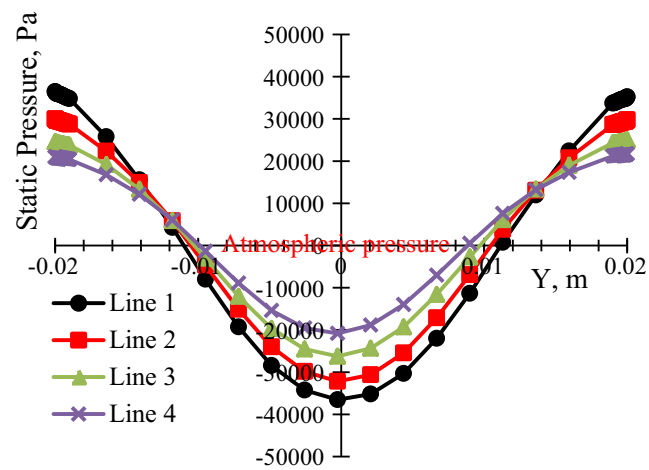

(d)

Fig. 10-Swirling steel flow characteristics in the SEN, $(a)$ total velocity, $(b)$ tangential velocity, $(c)$ vertical velocity, and $(d)$ pressure distribution.

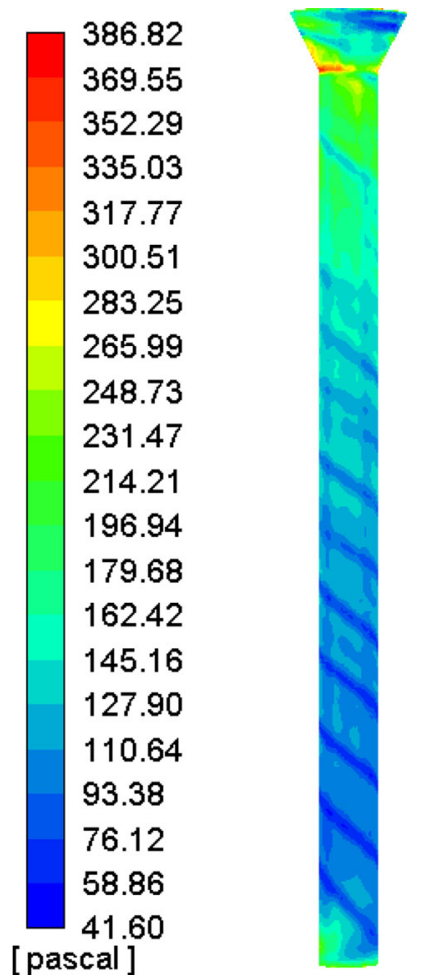

Fig. 11-Shear stress on the SEN wall.

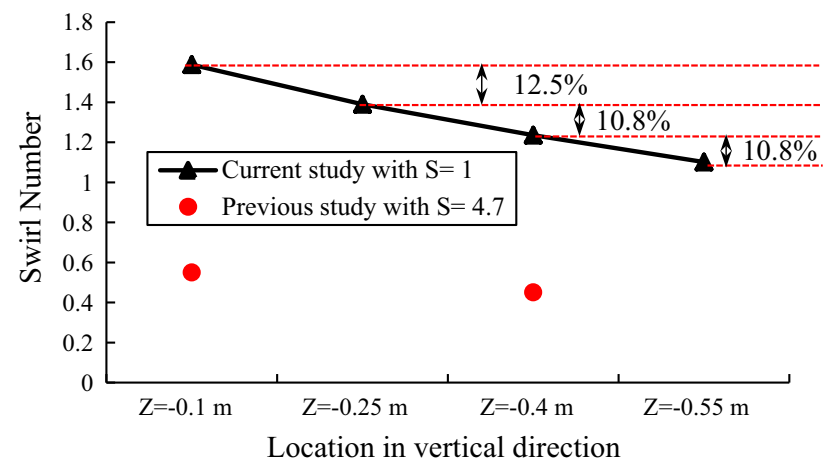

Fig. 12 - Comparison of Swirl Number in the SEN between the previous study ${ }^{[38]}$ and the current study ( $\mathrm{S}$ is the ratio of the inlet area of cylindrical tundish to the tundish SEN outlet area).

\section{DISCUSSION}

Both the water model experiment and the CFD simulation show that a strong swirling flow in the SEN was obtained by the newly designed cylindrical tundish. Figure 12 shows the Swirl Number in the current setup and its comparison with the previous study. ${ }^{[38]}$ The swirl number ${ }^{[33]}$ is calculated using the tangential mean velocity and the axial mean velocity, as shown in Eq. [5]. It can be seen from Figure 12 that with a proper geometry parameter the swirling flow intensity in 
the SEN of the cylindrical tundish design has the potential to reach a high level with the Swirl Number of around 1.6. Furthermore, the inlet flow velocity of the cylindrical tundish is an important parameter for the swirling flow intensity in the SEN. In addition, the decrease of the Swirl Number due to dissipation by wall shear stress can reach around 12.5 pct for the first 0.15 $m$ distance from Line 1 to Line 2. The value decreases to around 10.8 pct in the following distance from Line 2 to Line 3 as well as from Line 3 to Line 4 . This means that the dissipation rate of the Swirl Number is high when the Swirl Number is large.

$$
S_{\mathrm{w}}=\frac{2 W}{3 U}
$$

In the cylindrical tundish design, the rotational momentum of the swirling flow in the SEN comes from the rotational flow in the cylindrical part of the tundish. Therefore, a higher swirling flow intensity in the SEN may also correspond to a larger rotational steel flow velocity in the cylindrical tundish. Figure 13 shows the velocity contour at the $Y Z$ middle plane of the cylindrical tundish. It can be seen that the velocity at the tundish top can reach around $0.7 \mathrm{~m} / \mathrm{s}$ in the current setup. Therefore, methods like argon protection, instead of slag protection, during a casting are required to protect the steel flow surface from reoxidation by air in the cylindrical tundish, since the rotational flow is strong there. Because the volume of the cylindrical tundish is small, the residence time of the steel in the cylindrical tundish is expected to be short, more specifically around 150 seconds in the current numerical investigation. Therefore, the possibility of reoxidation of the steel under an argon protection atmosphere and its influence on steel quality is expected to be minor.

Currently, the studies of two other methods to produce a swirling flow are practiced. The first one is the electromagnetic stirring method. Yang et al. ${ }^{[34]}$ investigated the swirling flow in the SEN with electromagnetic stirring, where the SEN diameter, with the value of $0.04 \mathrm{~m}$, and the casting speed, with the steel flow velocity of around $1.1 \mathrm{~m} / \mathrm{s}$ at the SEN inlet, are the same as those in the current study. Figure 14 shows the vertical velocity distribution in the SEN from the current study and its comparison to the results reported by Yang et $a l^{[34]}$ with the magnetomotive force of 44,000 AT. It can be seen that in the SEN center region the vertical velocity from the current study is upwards, while the value is close to zero in the previous study. In the near-wall region, the vertical velocity of the current study is quite different from the previous study. This is due to the fact that in this study the turbulent boundary layer was solved using RSM combined with Stress-Omega submodel to obtain a better agreement with the experimental data. A good solution on the flow characteristics in the near-wall region is important for a good prediction of a swirling flow, since a large velocity gradient normally exists in the radial direction of a SEN cross section in a swirling flow. The maximum vertical velocity magnitude along Line 1 of the current study is similar to that at the end of the magnetic stirring region

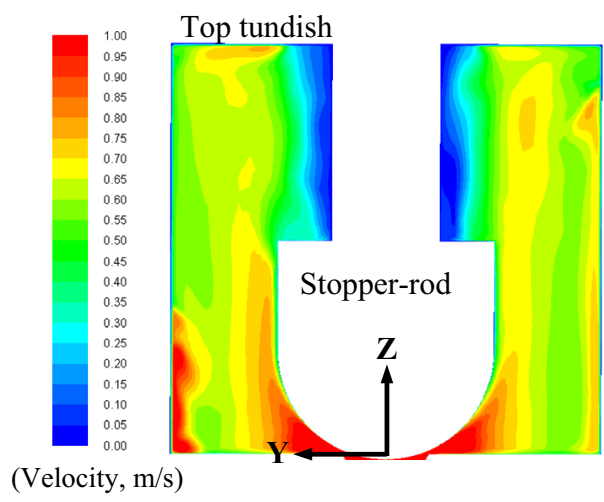

Fig. 13-Velocity contour at the $Y Z$ middle plane of the cylindrical tundish.

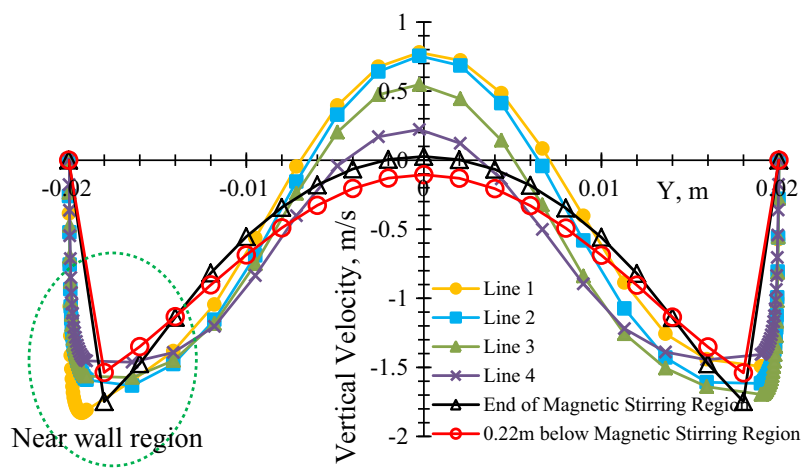

Fig. 14 - Comparison of vertical velocity distribution in the SEN between the current study and the previous study. ${ }^{[3]}$

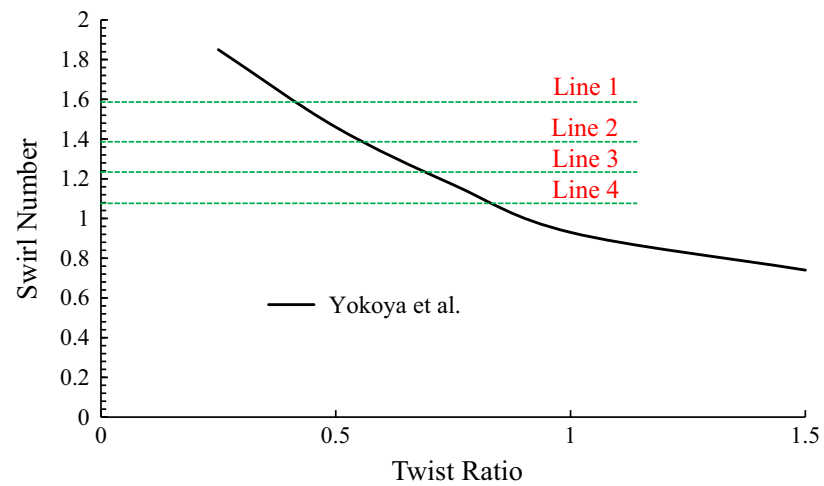

Fig. 15-Swirl number obtained by different twist ratios of swirl blades $^{[33]}$ and the level of swirl number obtained in this study.

in a previous study, with the values of around $1.7 \mathrm{~m} / \mathrm{s}$. This illustrates that the swirling flow intensity at Line 1 is similar to that obtained using electromagnetic stirring with the magnetomotive force of 44,000 AT. At the SEN outlet, the obtained swirling flow intensity with electromagnetic stirring is similar to that in Line $3(0.4 \mathrm{~m}$ below the SEN inlet) in this study. In summary, the cylindrical tundish can effectively produce a very strong swirling flow similar to that of electromagnetic stirring with the magnetomotive force of 44,000 AT. ${ }^{[34]}$ This is realized 
simply by changing the steel flow path in tundish by the current new design.

The swirl blade is another method that has been extensively investigated for producing a swirling flow in the SEN. Yokoya et al. ${ }^{[33]}$ studied the effect of twist ratio on the swirling flow intensity, which is represented by the Swirl Number shown in Eq. [5]. The twist ratio is defined as the length of the swirl blade in the axial direction twisted by 180 deg divided by the diameter of the swirl blade. Figure 15 shows the comparison of the Swirl Number obtained by different twist ratios of the swirl blade and that obtained in this study. It can be seen that the current cylindrical tundish can reach a similar intensity level of the swirling flow as that obtained by a swirl blade, i.e., the swirl number can reach around 1.6. However, in the current method, the limitations of the swirl blade method, such as the lifespan of the swirl blade and the clogging of the swirl blade by inclusion deposition, do not exist.

From the above discussion, it can be concluded that the cylindrical tundish method can produce a swirling flow with a similar intensity, with the swirl number in the range of 1 to 1.6 , as the other methods like electromagnetic stirring and swirl blade. However, it does not require the use of the electromagnetic equipment and electricity consumption, and it does not have limitations of the lifespan and clogging of the swirl blade. In an industrial application, a certain intensity of swirling flow in the SEN can be obtained by choosing proper parameters of the cylindrical tundish design, after considering the possibility of the refractory material erosion due to the high shear stress in a swirling flow which is a common issue for all swirling flows in a SEN. A systematical study to illustrate the effects of different parameters on the swirling flow intensity is still required in the future for a good design of the application in the production.

\section{CONCLUSIONS}

A newly designed cylindrical tundish, with the aim to obtain a swirling flow in a SEN in an economical way, was investigated using both water model experiments and numerical simulations. A high swirling flow intensity with the Swirl Number of around 1.6, in the SEN of the new tundish design with the area ratio of inlet to outlet of 1, was successfully obtained. In brief, the conclusions are as follows:

1. Water model experiment was carried out to validate the numerical model. The RSM model prediction was found to agree well to the PIV-measured water model results, compared to the $k-\varepsilon$ models. A strong swirling flow was observed in the experimental SEN.

2. High swirling flow intensity in the SEN was obtained under the current setup. The peak tangential velocity could reach a value of around $3.1 \mathrm{~m} / \mathrm{s}$. A high value of shear stress, with the maximum value of around $300 \mathrm{~Pa}$, was found on the SEN wall due to the swirling flow in the SEN. Some rotational momentum was lost due to dissipation from the wall shear stress. The swirling flow intensity in the SEN was reduced in the vertical direction with an increasing distance from the SEN inlet, with the obtained peak tangential velocity of $2.2 \mathrm{~m} / \mathrm{s}$ at $0.55 \mathrm{~m}$ from the SEN inlet (Line 4).

3. The swirling flow intensity obtained by the current setup was compared to those obtained with the other methods to produce swirling flow. The swirl number of the current setup can reach a value of 1.6. This swirling flow intensity can reach a similar level as the method of swirl blade and/or the electromagnetic stirring, while it is obtained simply by changing the steel flow path.

\section{OPEN ACCESS}

This article is distributed under the terms of the Creative Commons Attribution 4.0 International License (http://creativecommons.org/licenses/by/4.0/), which permits unrestricted use, distribution, and reproduction in any medium, provided you give appropriate credit to the original author(s) and the source, provide a link to the Creative Commons license, and indicate if changes were made.

\section{REFERENCES}

1. J. Szekely and R.T. Yadoya: Metall. Mater. Trans., 1973, vol. 4, pp. 1379-88.

2. M. Xu and M. Zhu: ISIJ Int., 2015, vol. 55, pp. 791-98.

3. F.M. Najjar, B.G. Thomas, and D.E. Hershey: Metall. Mater. Trans. B, 1995, vol. 26B, pp. 749-65.

4. B.G. Thomas, L.J. Mika, and F.M. Najjar: Metall. Mater. Trans. B, 1990, vol. 21B, pp. 387-400.

5. H. Bai and B.G. Thomas: Metall. Mater. Trans. B, 2001, vol. 32B, pp. 269-84.

6. I. Calderon-Ramos, R.D. Morales, S. Garcia-Hernandez, and A. Ceballos-Huerta: ISIJ Int., 2014, vol. 54, pp. 1797-1806.

7. I. Calderon-Ramos, R.D. Morales, and M. Salazar-Campoy: Steel Res. Int., 2015, vol. 86, pp. 1610-21.

8. I. Calderon-Ramos and R.D. Morales: Metall. Mater. Trans. B, 2015, vol. 46B, pp. 1314-25.

9. M. Salazar-Campoy, R.D. Morales, A. Najera-Bastida, V. Cedillo-Hernandez, and J.C. Delgado-Pureco: Metall. Mater. Trans. B, 2017, vol. 48B, pp. 1376-89.

10. H. Sun and J. Zhang: Metall. Mater. Trans. B, 2014, vol. 45B, pp. 936-46.

11. H. Sun and L. Li: Ironmak. Steelmak., 2016, vol. 43, pp. 228-33.

12. Q. Fang, H. Ni, H. Zhang, B. Wang, and Z. Lv: Metals, 2017, DOI: $10.3390 / \operatorname{met} 7040146$.

13. A. Sen, B. Prasad, J.K. Sahu, and J.N. Tiwari: I.O.P. Conf. Ser. Mater. Sci. Eng., 2015, vol. 75, p. 012006.

14. R. Sambasivam: Ironmak. Steelmak., 2006, vol. 33, pp. 439-53.

15. B.G. Thomas, X. Huang, and R.C. Sussman: Metall. Mater. Trans. B, 1994, vol. 25B, pp. 527-47.

16. H. Bai and B.G. Thomas: Metall. Mater. Trans. B, 2001, vol. 32B, pp. 253-67.

17. H. Bai and B.G. Thomas: Metall. Mater. Trans. B, 2001, vol. 32B, pp. 707-22.

18. C. Pfeiler, M. Wu, and A. Ludwig: Mater. Sci. Eng. A, 2005, vols. 413-414, pp. 115-20.

19. S. Cho, B.G. Thomas, and S. Kim: Metall. Mater. Trans. B, 2016, vol. 47B, pp. 3080-98.

20. K. Jin, B.G. Thomas, and X. Ruan: Metall. Mater. Trans. B, 2016, vol. 47B, pp. 548-65.

21. S. Pirker, D. Kahrimanovic, and S. Schneiderbauer: Metall. Mater. Trans. B, 2015, vol. 46B, pp. 953-59. 
22. L. Zhang, Y. Wang, and X. Zuo: Metall. Mater. Trans. B, 2008, vol. 39B, pp. 534-50.

23. B.G. Thomas and L. Zhang: ISIJ Int., 2001, vol. 41, pp. 1181-93.

24. K. Takatani: ISIJ Int., 2003, vol. 43, pp. 915-22.

25. K. Cukierski and B.G. Thomas: Metall. Mater. Trans. B, 2008, vol. 39B, pp. 94-107.

26. R. Singh, B.G. Thomas, and S.P. Vanka: Metall. Mater. Trans. B, 2014, vol. 45B, pp. 1098-115.

27. S. Yokoya, S. Takagi, M. Iguchi, Y. Asako, R. Westoff, and S. Hara: ISIJ Int., 1998, vol. 38, pp. 827-33.

28. S. Yokoya, S. Takagi, M. Iguchi, K. Marukawa, and S. Hara: ISIJ Int., 2000, vol. 40, pp. 578-83.

29. S. Yokoya, Y. Asako, S. Hara, and J. Szekely: ISIJ Int., 1994, vol. 34 , pp. $883-88$.

30. Y. Tsukaguchi, O. Nakamura, P. Jönsson, S. Yokoya, T. Tanaka, and S. Hara: ISIJ Int., 2007, vol. 47, pp. 1436-43.

31. S. Yokoya, R. Westoff, Y. Asako, S. Hara, and J. Szekely: ISIJ Int., 1994, vol. 34, pp. 889-95.

32. Y. Tsukaguchi, H. Hayashi, H. Kurimoto, S. Yokoya, K. Marukawa, and T. Tanaka: ISIJ Int., 2010, vol. 50, pp. 721-29.

33. S. Yokoya, S. Takagi, M. Iguchi, K. Marukawa, W. Yasugaira, and S. Hara: ISIJ Int., 2000, vol. 40, pp. 584-88.

34. Y. Yang, P.G. Jönsson, M. Ersson, and K. Nakajima: Steel Res. Int., 2015, vol. 86, pp. 341-60.

35. D. Li, Z. Su, J. Chen, Q. Wang, Y. Yang, K. Nakajima, K. Marukawai, and J. He: ISIJ Int., 2013, vol. 53, pp. 1187-94.
36. H. Liu, M. Xu, S. Qiu, and H. Zhang: Metall. Mater. Trans. B, 2012, vol. 43B, pp. 1657-75.

37. L.B. Trindade, J.E.A. Nadalon, A.C. Contini, and R.C. Barroso: Steel Res. Int., 2017, vol. 88, p. 1600319.

38. P. Ni, L. Jonsson, M. Ersson, and P. Jönsson: Steel Res. Int., 2016, vol. 87 , pp. 1356-65.

39. K. Chattopadhyay, M. Isac, and R. Guthrie: ISIJ Int., 2010, vol. 50, pp. 331-48.

40. Y. Sahai: Metall. Mater. Trans. B, 2016, vol. 47B, pp. 2095106.

41. H. Bai, M. Ersson, and P.G. Jönsson: ISIJ Int., 2016, vol. 56, pp. 1404-12.

42. S.V. Patankar: Numerical Heat Transfer and Fluid Flow, Hemispere Publishing Corp, New York, 1980.

43. T.-H. Shih, W.W. Liou, A. Shabbir, Z. Yang, and J. Zhu: Comput. Fluids, 1995, vol. 24, pp. 227-38.

44. ANSYS Fluent Theory Guide, Release 17.0, 2016, 85

45. H.K. Versteeg and W. Malalasekera: An Introduction to Computational Fluid Dynamics, The Finite Volume Method, 2nd ed., Pearson Education Limited, UK, 2007, pp. 80-85.

46. B.E. Launder, G.J. Reece, and W. Rodi: J. Fluid Mech., 1975, vol. 68 , pp. $537-66$.

47. F.S. Lien and M.A. Leschziner: Comput. Fluids., 1994, vol. 23, pp. 983-1004.

48. D.C. Wilcox: Turbulence Modeling for CFD, DCW Industries, Inc., La Canada, 1998. 